\title{
Carcinoembryonic antigen is the preferred biomarker for in vivo colorectal cancer targeting
}

\author{
J P Tiernan ${ }^{*}, 1,2$, S L Perry ${ }^{1}$, E T Verghese ${ }^{1,3}$, N P West ${ }^{1,3}$, S Yeluri ${ }^{1}$, D G Jayne ${ }^{1,2}$ and T A Hughes ${ }^{1}$ \\ ${ }^{1}$ Leeds Institute of Molecular Medicine, Wellcome Trust Brenner Building, St. James's University Hospital, University of Leeds, \\ Leeds LS9 7TF, UK; ${ }^{2}$ John Goligher Colorectal Unit, St James's University Hospital, Leeds, UK and ${ }^{3}$ Department of Histopathology, \\ Bexley Wing, St. James's University Hospital, Leeds, UK
}

Background: Colorectal cancer-specific biomarkers have been used as molecular targets for fluorescent intra-operative imaging, targeted PET/MRI, and selective cytotoxic drug delivery yet the selection of biomarkers used is rarely evidence-based. We evaluated sensitivities and specificites of four of the most commonly used markers: carcinoembryonic antigen (CEA), tumourassociated glycoprotein-72 (TAG-72), folate receptor- $\alpha$ (FR $\alpha$ ) and Epithelial growth factor receptor (EGFR).

Methods: Marker expression was evaluated semi-quantitatively in matched mucosal and colorectal cancer tissues from 280 patients using immunohistochemistry (scores of $0-15$ ). Matched positive and negative lymph nodes from 18 patients were also examined.

Results: Markers were more highly expressed in tumour tissue than in matched normal tissue in $98.8 \%, 79.0 \%, 37.1 \%$ and $32.8 \%$ of cases for CEA, TAG-72, FR $\alpha$ and EGFR, respectively. Carcinoembryonic antigen showed the greatest differential expression, with tumours scoring a mean of 10.8 points higher than normal tissues $(95 \% \mathrm{Cl} 10.31-11.21, P<0.001)$. Similarly, CEA showed the greatest differential expression between positive and negative lymph nodes. Receiver operating characteristic analyses showed CEA to have the best sensitivity (93.7\%) and specificity (96.1\%) for colorectal cancer detection.

Conclusion: Carcinoembryonic antigen has the greatest potential to allow highly specific tumour imaging and drug delivery; future translational research should aim to exploit this.

There is much interest in developing strategies for tumour-specific delivery of agents to increase our diagnostic capability or enhance the selectivity and effectiveness of therapeutics. These strategies rely on the ability to target tumour cells accurately using biomarkers that are differentially expressed between tumour and normal tissue. In colorectal cancer, the most commonly used biomarkers include carcinoembryonic antigen (CEA) (Muguruma et al, 1999; Sharkey et al, 2005; Kaushal et al, 2008; Yazaki and Kassa et al 2008; Heine et al, 2011), tumour-associated glycoprotein-72 (TAG-72) (Tang et al, 2007; Chen et al, 2008; Zou et al, 2009; Chen et al, 2011), Epithelial growth factor receptor (EGFR) (Goetz et al, 2010; Jeong et al, 2012; Qi et al, 2012), and folate receptor- $\alpha(\mathrm{FR} \alpha)($ Reddy and Low, 1998; Chen et al, 2005; Yang et al, 2010). Carcinoembryonic antigen and TAG-72 are membrane-bound glycoproteins that are expressed in over $80 \%$ of colorectal cancers with relatively little expression in normal mucosa (Johnson et al, 1986; Jantscheff et al, 2003). Folate receptor- $\alpha$ is a membrane-bound protein that binds and transports folic acid and is overexpressed in epithelial-derived cancers, including those of the colorectum (Shia et al, 2008). It appears to be expressed relatively infrequently in colorectal tumours but is absent in the vast majority of normal tissues, hinting at a potentially high specificity (Shia et al, 2008). Epithelial growth factor receptor is a well-known target for anti-cancer therapies but

*Correspondence: JP Tiernan; E-mail: jimtiernan1@gmail.com

Received 29 October 2012; revised 11 December 2012; accepted 12 December 2012; published online 15 January 2013 
the literature concerning the degree and frequency of EGFR overexpression in colorectal cancer is contradictory, with reported expression varying from $33 \%$ to $97 \%$ of cases (Koretz et al, 1990; Lee et al, 2002; Spano et al, 2005; Bhargava et al, 2006). It is also reported to be expressed in up to $48 \%$ of normal colorectal samples (Koretz et al, 1990), which could compromise its specificity for cancer tissue.

Identification of biomarkers that are sensitive and specific for colorectal cancer opens up many avenues for diagnostic and therapeutic exploitation. The ability to visualise tumours and their metastases during surgery may facilitate more accurate and disease-specific operations. Fluorescence-based, laparoscopic imaging, using antibodies targeting antigens found on tumour cells, has already shown considerable potential (Mahmood, 2010; Tiernan et al, 2012). In non-invasive imaging, iodine-124 labelled antibodies to CEA have been administered to enhance PET cancer scanning (Schoffelen et al, 2010; Boerman and Oyen, 2011; Carrasquillo et al, 2011; Meller et al, 2011; O'Donoghue et al, 2011; Schoffelen et al, 2012), and CEA antibodies have been conjugated to iron oxide nanoparticles to improve MRI imaging (Vigour et al, 2010). In therapeutic applications, radioisotope antibodies, usually directed towards CEA or TAG-72, have been used to deliver tumour selective radiotherapy (Meredith et al, 1996; Meyer et al, 2009; de Jong et al, 2011) and have been shown to be particularly effective in small-volume disease (Koppe et al, 2005; Barbet et al, 2012). Similarly, targeted cytotoxic drug delivery has the potential to deliver high-dose chemotherapy to cancer cells, while limiting damage to normal cells, and has utilised a variety of biomarkers, including FR $\alpha$ (Li et al, 2011; Zhang et al, 2012), EGFR (Kopansky et al, 2011) and CEA (Conaghan et al, 2008).

A surprising feature of all the above examples of targeted tumour delivery is that the choice of biomarker used is rarely justified in terms of its tumour sensitivity and specificity. The characteristics of suitable cancer biomarkers are that they must be highly expressed in a large majority of tumours and have low or no expression in normal tissue, encompassing the normal tissue from which the tumour is derived and - ideally - most or all normal adult tissues accessible to systemic delivery. Suitable molecules must also be located on the external facing surfaces of cancer cells so as to be accessible to systemically delivered recognition molecules. To our knowledge, expression of the most commonly used markers for colorectal cancer has never been rigorously evaluated in a well-defined cohort of cancer and normal tissue. We aimed to evaluate the sensitivity and specificity of the four most commonly used markers for colorectal cancer, CEA, TAG-72, FR $\alpha$, and EGFR, to define which is most suitable for in vivo tumour targeting.

\section{MATERIALS AND METHODS}

Ethical issues and patient cohort. Ethical approval was obtained from the National Research Ethics Service (London-Dulwich Committee), reference 12/LO/1327. Formalin-fixed paraffinembedded tissue blocks containing primary colorectal carcinoma and matched normal colorectal mucosa, collected prospectively for the MRC CLASICC trial (Guillou et al, 2005), were available from 280 patients. Table 1 shows patient and tumour characteristics. Formalin-fixed paraffin-embedded blocks containing mesenteric lymph nodes (both tumour cell positive and negative) were available for 18 of the patients.

Antibodies and immunohistochemistry. Antibody suppliers and evidence for antibody specificity are described below. A5B7 humanised anti-CEA antibody was supplied by the Cancer Research UK Biotherapeutics Development Unit (Clare Hall Laboratories, UK) and has been used in clinical trials of targeted

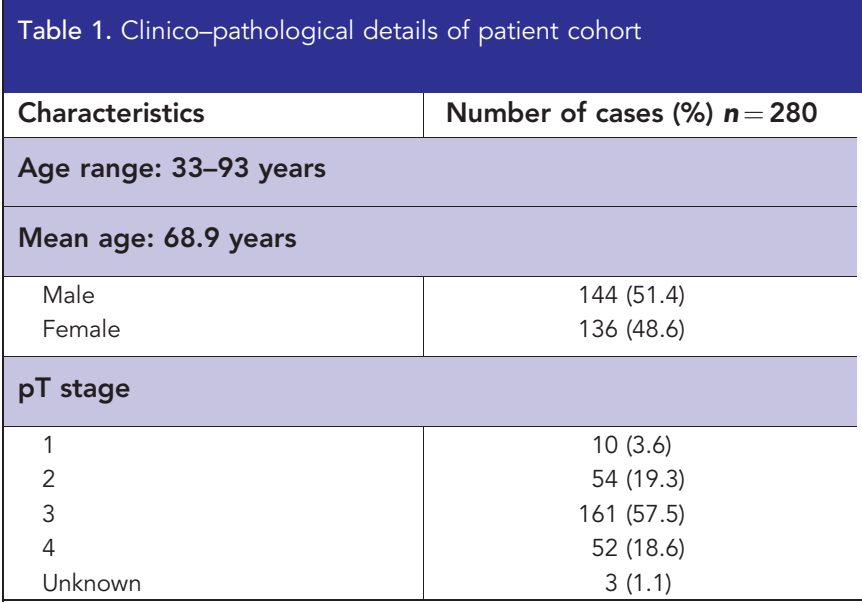

therapies (Dawson et al, 1991; Meyer et al, 2009). Mouse antiTAG-72 antibody (clone CC49; Santa Cruz, CA, USA) has been used widely to target colorectal cancer in radioimmunoguided surgery (Sun et al, 2007; Povoski et al, 2012). Mouse anti-EGFR antibody (clone 31G7; Invitrogen, Carlsbad, CA, USA) has been shown to be highly sensitive in detection of EGFR positive colorectal tumours (Buckley and Kakar, 2007). Mouse anti-FR- $\alpha$ antibody (clone BN3.2; Leica Biosystems, Newcastle, UK) has been validated across a wide range of tissues, including colorectal tissue (Smith et al, 2007). Antibodies were optimised for use in immunohistochemistry on whole colorectal cancer tissue sections to give a broad range of epithelial staining intensities with minimal background staining. Tissue microarrays were constructed from formalin-fixed paraffin-embedded resection samples of colorectal cancer and matched normal colorectal mucosa using $0.6-\mathrm{mm}$ cores. For each patient, three cores were selected from the most representative tumour area (as determined by haematoxylin and eosin staining) and three cores from normal mucosa. Tissue microarray blocks or lymph nodes blocks were sectioned onto SuperFrost Plus microscope slides (Menzel-Glaser, Braunschweig, Germany), dewaxed with xylene and rehydrated through ethanol before rinsing in water for $5 \mathrm{~min}$. Epitopes were retrieved either by heating slides in pre-warmed $10 \mathrm{~mm}$ citric acid buffer $(\mathrm{pH} 6.0$, microwave $900 \mathrm{~W}, 10 \mathrm{~min}$; anti-CEA and anti-TAG-72), using a pressure cooker (anti-FR $\alpha$ ), or incubating in proteinase $\mathrm{K}$ ( $25 \mathrm{~min}$, $37^{\circ} \mathrm{C}$; anti-EGFR). Endogenous peroxidase activity was blocked with $0.6 \%$ hydrogen peroxide for $10 \mathrm{~min}$ before rinsing in water for $5 \mathrm{~min}$. Slides were mounted in Sequenzas (Thermo Scientific, Waltham, MA, USA) and rinsed with tris-buffered saline (TBS) followed by antibody diluent reagent solution (Invitrogen). Primary antibodies were used in diluent reagent at $1: 100$, $1: 150000,1: 25,1: 50$ and $1: 50$ for anti-TAG-72, anti-CEA, anti-FR $\alpha$, and anti-EGFR, respectively. Incubations were at room temperature for $1 \mathrm{~h}$ (CEA, TAG-72) or overnight at $4{ }^{\circ} \mathrm{C}(\mathrm{FR} \alpha$, EGFR). Slides were washed twice with TBS-T (TBS, 10\% Tween 20) and once with TBS before incubating with an appropriate horseradish peroxidise conjugated secondary antibody (Dako, Glostrup, Denmark) for $30 \mathrm{~min}$ at room temperature. The slides were washed with TBS-T and TBS. $100 \mu \mathrm{l}$ of 3,3'-diaminobenzidene (Dako) solution was added to each slide for $10 \mathrm{~min}$ before a 5 min wash in water. Slides were then stained with haematoxylin, dehydrated with ethanol and xylene, and mounted with DPX Histology mountant (Fluka, St. Louis, MO, USA).

Scoring and statistical analyses. Slides were digitally scanned using Scanscope XT (Aperio, Vista, CA, USA) at $20 \times$ magnification and were observed for scoring using ImageScope v11 (Aperio). Staining was assessed semi-quantitatively using a bespoke scoring 
system developed in consultation with two pathologists (ETV and NPW). Cores were scored for intensity of epithelial cell staining ( 0 , no staining; 1 , mild; 2 , moderate; 3 , strong) and percentage of epithelial cells staining positively $(0,<5 \% ; 1,5-20 \% ; 2,21-40 \% ; 3$, $41-60 \% ; 4,61-80 \% ; 5,81-100 \%)$. These scores were multiplied to give final scores of $0-15$. Tumour cores with no tumour cells and normal cores with no epithelial cells visible were discounted. Carcinoembryonic antigen and TAG-72 were scored for apical membranous staining only. Folate receptor- $\alpha$ showed mild cytoplasmic staining only, and was scored solely for this. Epithelial growth factor receptor showed membranous, and - more rarely cytoplasmic and nuclear staining. However, following established literature (Scartozzi et al, 2004; Buckley and Kakar, 2007) EGFR was scored for membranous expression only. Two independent observers were involved in the scoring: JPT scored all cores and ETV scored cores representing $15 \%$ of the cases. Scoring reproducibility was determined for each antibody using the intra-class correlation coefficient; the process of calculating the mean score for each patient led to 61 possible outcomes, and therefore the data were treated as continuous rather than categorical. Scores for each case of tumour or normal tissue were means of scores allocated by JPT for each core from that tissue. If only one core score was available, for example owing to lack of appropriate cell types or core loss, this single score was used; a method that has been validated previously (Camp et al, 2000; Torhorst et al, 2001)). Means for normal and tumour tissue were compared using Wilcoxon signed-rank tests for paired nonparametric data. Sensitivities and specificities were calculated from the mean scores for tumour and normal tissue expression for each case using two different cutoff points: the 95th percentile of the normal tissue score distribution and optimal cutoffs identified by receiver operating characteristic curves (Maraqa et al, 2008).

\section{RESULTS}

Expression of markers in normal colorectal tissue and tumours. We examined expression of CEA, TAG-72, FR $\alpha$ and EGFR in a cohort of 280 colorectal carcinomas and matched normal tissues. Clinical and pathological features of this cohort are shown in Table 1. Representative images of staining for each antigen in both normal and tumour tissues are shown in Figure 1. All four markers showed epithelial cell specific staining that was diffuse with some luminal accentuation. No staining for any marker was noted in blood cells within the sections, suggesting that expression in this compartment is negligible. The intra-class correlation coefficient was 0.89 , demonstrating good agreement between scorers. Both the proportion of epithelial cells staining positively and the intensity of staining varied widely throughout the cohort in normal and tumour tissues (Figure 2). Strongly positive staining in normal tissues was relatively uncommon for all antigens, especially for FR $\alpha$ (negative in over 99\% at the concentrations used). In the tumours, by contrast, strongly positive staining was prevalent for CEA and TAG-72, and was more common for FR $\alpha$ than in normal tissue although tumours were also mostly negative (61\%). Epithelial growth factor receptor staining in tumours showed a similar range of scores to those in normal tissues. Carcinoembryonic antigen, TAG-72 and FR $\alpha$, but not EGFR, were significantly more highly expressed in colorectal tumour tissues than in the normal tissues $(P<0.001$; Table 2).

Differential expression between matched normal and tumour tissue. If markers are to be used for tumour-specific imaging or therapeutic delivery, the frequency and the magnitude of increased expression in tumours are key parameters. Expression scores were higher in tumours as compared with matched normal tissues in $98.8 \%, 79.0 \%, 37.1 \%$ and $32.8 \%$ of cases for CEA, TAG-72, FR $\alpha$ and EGFR, respectively. Although this percentage is relatively low for $F R \alpha$ it should be noted that expression was higher in tumours as compared with matched normal tissue in almost all cases where positive staining was detected in either tissue. However, in the case of EGFR, expression was higher in normal tissue (34\% of cases) more frequently than in tumours (33\% of cases), indicating little or no bias for tumour-specific expression. We have estimated the magnitude of the differences in expression between matched tumour and normal tissues as the tumour expression score minus the normal expression score (Figure 3). Carcinoembryonic antigen demonstrated the greatest difference in expression, with tumours scoring on average 10.8 (95\% CI 10.31-11.21) points higher than normal tissues. This difference was more than twice that of the next best marker, TAG-72, which showed tumour expression 5.1 (95\% CI 4.35-5.77) points higher than normal tissue, while FR $\alpha$ and EGFR showed only very small increases in expression within the tumours.

Expression of markers in lymph nodes. If markers are to be used for imaging or therapeutic targeting of tumour deposits within
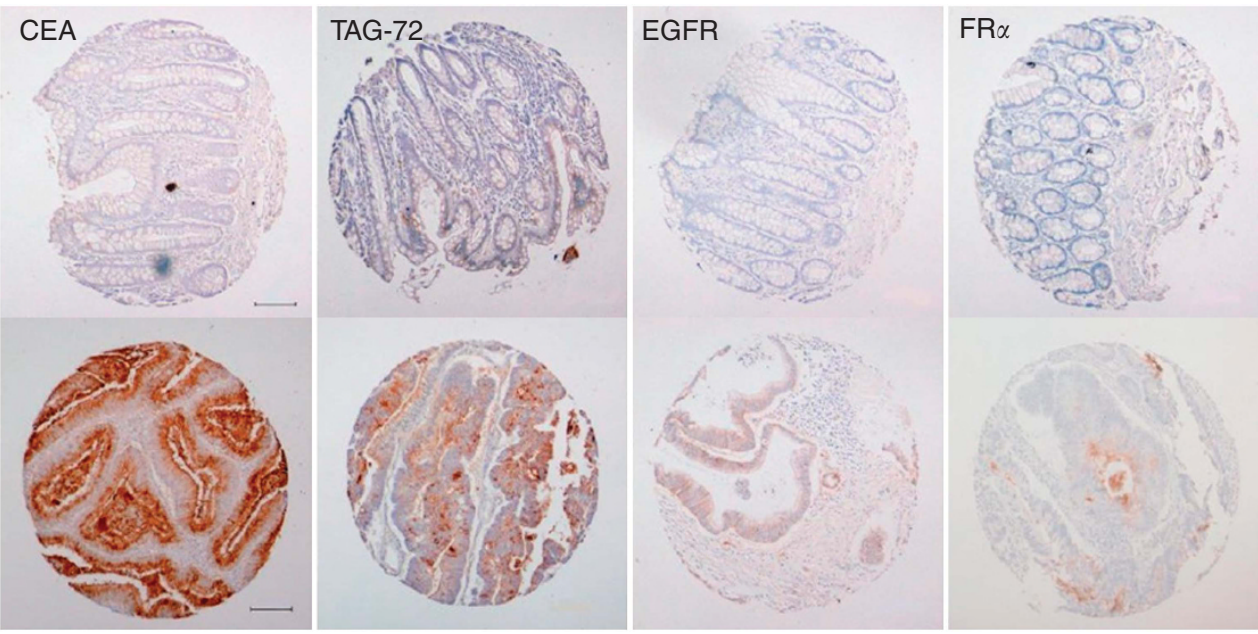

Figure 1. Representative tissue microarray cores of normal colorectal tissue (top row) and colorectal tumours (bottom row) showing immunoreactivity as labelled. The normal tissue cores shown demonstrate the median score for that antigen in normal colorectal tissues (CEA $=1$; TAG$72=2 ; E G F R=0 ; F R \alpha=0)$. The tumour cores shown demonstrate the median positive score for that antigen in colorectal tumours (CEA = 15; TAG$72=10 ; \mathrm{EGFR}=2 ; \mathrm{FR} \alpha=1)$. Scale bar $=100 \mu \mathrm{m}$. 

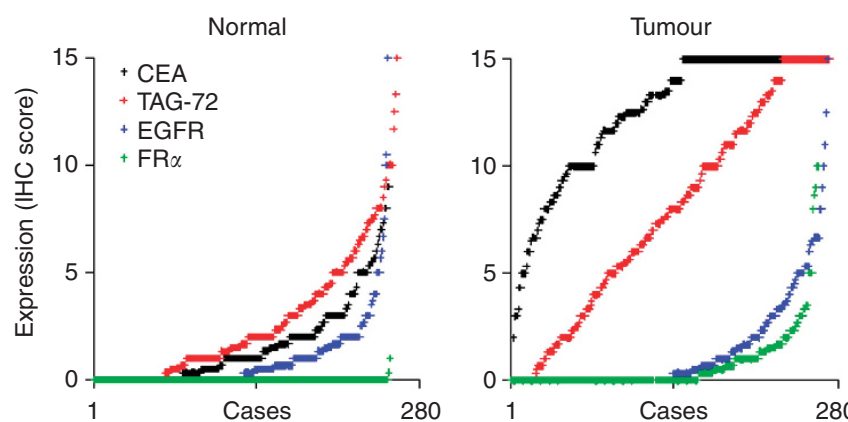

Figure 2. Expression levels of CEA, TAG-72, EGFR or FR $\alpha$ in normal colorectal tissue (left) and in colorectal tumours (right). Expression levels were determined in $\mathbf{2 8 0}$ matched normal and tumour tissues by immunohistochemistry using semi-quantitative scores of 0-15. The scores for each marker are arranged independently in ascending order to demonstrate the distributions across the cohort.

Table 2. CEA, TAG-72 and FR $\alpha$ are significantly more highly expressed in colorectal tumour tissue than matched normal tissue

\begin{tabular}{l|c|c|c|}
\hline Antigen & Mean normal score & Mean tumour score & P-value \\
\hline CEA & 1.7 & 12.4 & $<0.001$ \\
\hline TAG-72 & 2.7 & 7.8 & $<0.001$ \\
\hline FR $\alpha$ & 0.0 & 0.7 & $<0.001$ \\
\hline EGFR & 0.9 & 1.3 & 0.08 \\
\hline \multicolumn{3}{|l}{} \\
$\begin{array}{l}\text { Abbreviations: CEA = carcinoembryonic antigen; EGFR = Epithelial growth factor receptor; } \\
\text { FR } \alpha=\text { folate receptor- } \alpha \text {; TAG-72 = tumour-associated glycoprotein-72. }\end{array}$
\end{tabular}
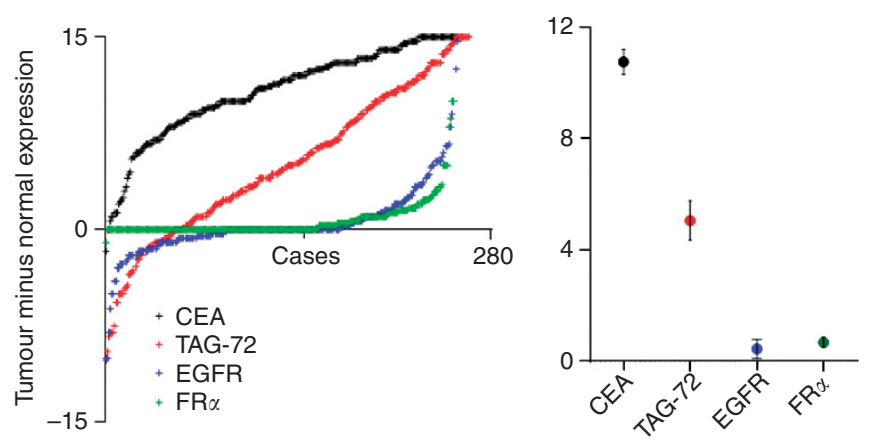

Figure 3. Carcinoembryonic antigen shows the most consistent overexpression in tumour tissues and the greatest differential expression between matched normal and tumour tissues. Left: Expression scores for normal tissues were subtracted from those for matched tumour tissues to quantify the degree of tumour overexpression for each case. Overexpression scores for each marker are arranged in ascending order to demonstrate the distributions across the cohort (left). Minus scores reflect cases where tumour expression was lower than expression in the matched normal tissue. Mean overexpression scores (central marker) with 95\% confidence intervals (error bars) are also shown (right).

lymph nodes, marker expression both of tumour cells in tumourcell positive lymph nodes and of normal lymph node tissues are critical. We examined expression of the four markers in lymph nodes taken during resection from 18 of the patients from our cohort. In each case, we examined a node found to contain metastatic tumour cells ('positive') and a node that was clear of metastatic deposits ('negative') (Figure 4). Expression of all
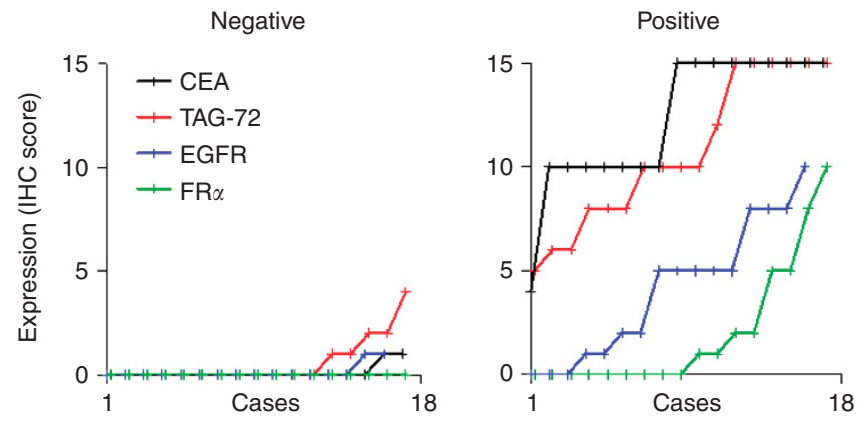

Figure 4. Expression levels of CEA, TAG-72, EGFR or FR $\alpha$ in lymph nodes, containing colorectal tumour deposits ('positive'; right) and in matched lymph nodes lacking tumour cells ('negative'; left). Expression levels were determined by immunohistochemistry using scores of 0-15 in 18 cases. The scores for each marker are arranged independently in ascending order to demonstrate the distributions across the cohort (note: datapoints are linked by lines to aid interpretation of the distributions not to imply adjacent datapoints are directly related).

markers was uncommon in negative nodes; TAG-72 showed the most staining, being expressed at only low levels by cells in the germinal centres in 5 out of 18 cases. The distributions of expression in positive nodes were similar to the patterns seen in primary tumours, with prevalent and strong expression of CEA and TAG-72, and less frequent and weaker expression of FR $\alpha$ and EGFR.

Specificity and sensitivity of markers for tumour detection. Accurate imaging of tumours based on the expression of any marker is heavily influenced by the limit of detection of the imaging system for marker expression. We have modelled this influence for each marker by examining what proportion of tumours would be successfully visualised when different expression scores were defined as the limit of detection; this is the sensitivity. We have also tested what proportion of normal tissues would be 'invisible', as required for tumour-specific imaging, using the same limits; this is the specificity. First, we arbitrarily set this cutoff point as the 95th percentile of the normal score distribution, thereby tolerating a $5 \%$ chance of incorrectly detecting normal tissue as positive (a specificity of 95\%). This cutoff gave sensitivities of 93.7\%, 45.4\%, 39.3\% and $11.8 \%$ for CEA, TAG-72, FR $\alpha$ and EGFR, respectively. We then plotted a ROC curve for each marker (Supplementary Figure S1) and used these to select the cutoff scores that gave the greatest combined sensitivity and specificity. These cutoff scores gave sensitivities and specificities of $93.7 \%$ and 96.1\% for CEA, $70.3 \%$ and $78.5 \%$ for TAG-72, 39.3\% and $99.2 \%$ for $\mathrm{FR} \alpha$, and $21.7 \%$ and $90.5 \%$ for EGFR.

\section{DISCUSSION}

In vivo tumour-specific targeting is a central requirement of many novel diagnostic and therapeutic strategies being developed for cancer. In colorectal cancer, the ability to detect and stage cancers intra-operatively has the potential to improve patient outcomes by accurate determination of resection margins and assessment of disease dissemination. Similarly, tumour-specific delivery of cytotoxic drugs or contrast agents for enhanced imaging has the potential to improve adjuvant treatment and diagnosis, respectively. Experimental work to date has relied mainly on antibodies directed at cell membrane proteins, such as CEA, TAG-72, FR $\alpha$ or EGFR (Reddy and Low, 1998; Muguruma et al, 1999; Zou et al, 2009; Goetz et al, 2010), although the field is advancing with the 
introduction of aptamer-based approaches. Surprisingly, given the dependency on accurate biomarker localisation, the selection of the markers used for tumour targeting is rarely justified based on their sensitivity or specificity. One would not contemplate using a marker giving poor specificity and sensitivity in routine laboratory analysis, and the same stringent criteria should therefore apply to in vivo tumour identification.

We examined the expression of four most commonly used colorectal cancer biomarkers in a large cohort of matched normal and tumour tissue using immunohistochemistry to determine their potential suitability for in vivo diagnostic and therapeutic application. Markers proving unsuitable in this analysis would most likely have no potential utility for the in vivo applications, which are even further limited by additional variables, such as tissue penetration, immunological response, and expression of markers within other normal tissues. To make our assessment we investigated three key criteria: (i) the proportion of the cohort in which tumours stained positively for markers, (ii) the proportion of the cohort in which tumours stained more strongly for markers than the matched normal tissues, and (iii) the magnitude of overexpression in tumours. Carcinoembryonic antigen out-performed other markers dramatically in all three measures, showing the most frequent tumour expression, and the most frequent and greatest tumour overexpression (Figures 2 and 3). In particular, differential CEA expression within normal/tumour pairs was notably greater as compared with other markers, providing evidence that CEA is the most reliable marker for differentiating between normal and tumour tissue. In the context of lymph nodes, CEA was again the superior target, with high levels and frequency of expression within positive nodes, and only minimal expression in normal lymph node tissue (Figure 4).

In practical imaging situations, the threshold, or cutoff, used to differentiate between normal and tumour would be determined by the user, by adjusting the signal gain. This could be altered to favour either sensitivity (lowering the cutoff to detect tumours more easily at the risk of detecting normal tissue erroneously) or specificity (raising the cutoff to avoid detection of normal tissue at the risk of missing tumour cells). We quantified the abilities of the markers to be used in tumour cell detection using their optimal cutoffs, as determined using ROC analyses, in terms of sensitivity (proportion of tumours correctly detected) and specificity (proportion of normal tissues correctly not detected). Carcinoembryonic antigen was the most sensitive marker by a considerable margin $(93.7 \%$, as compared with the nearest alternative TAG-72 at $70.3 \%)$, and was also highly specific $(96.1 \%)$. Folate receptor- $\alpha$ was the most specific marker (99.2\%); however, its utility is limited by the fact that it was not detectable in the majority of tumours, as previously reported (Shia et al, 2008), resulting in a poor sensitivity (39.3\%). In addition, the magnitude of differential expression between normal and tumour was relatively narrow, providing less security in determining tumour or normal identities. Most notably, EGFR was a surprisingly poor marker, being detected in less than half the tumours and being commonly more highly expressed in normal tissues than in tumours. For applications aiming at targeted delivery of therapeutics, similar considerations apply. Markers must allow a balance between ensuring tumour cells receive the cytotoxic insult while minimising collateral damage in normal cells that may express the antigen. In this context, $\mathrm{FR} \alpha$ may be an appropriate target in the tumours that express it, with very high specificity allowing minimal damage to normal cells. However, CEA is more suitable in a much larger proportion of tumours, accepting that normal tissues may suffer some dose of drug, albeit a much lower dose than the tumour cells.

We therefore conclude that of the four biomarkers tested, CEA alone is the most suitable for tumour targeting, and this should be reflected in future strategies for in vivo tumour diagnosis and therapeutic delivery.

\section{ACKNOWLEDGEMENTS}

This work was supported by Cancer Research UK (JPT), the MRC (ETV) and Yorkshire Cancer Research (NPW, SY). We thank Clare Hall Laboratories (Cancer Research UK) for kindly providing the A5B7 antibody.

\section{REFERENCES}

Barbet J, Bardies M, Bourgeois M, Chatal J-F, Cherel M, Davodeau F, FaivreChauvet A, Gestin J-F, Kraeber-Bodere F (2012) Radiolabeled antibodies for cancer imaging and therapy. Methods Mol Biol 907: 681-697.

Bhargava R, Chen B, Klimstra DS, Saltz LB, Hedvat C, Tang LH, Gerald W, Teruya-Feldstein J, Paty PB, Qin J, Shia J (2006) Comparison of two antibodies for immunohistochemical evaluation of epidermal growth factor receptor expression in colorectal carcinomas, adenomas, and normal mucosa. Cancer 106(8): 1857-1862.

Boerman OC, Oyen WJG (2011) Immuno-PET of cancer: a revival of antibody imaging. J Nucl Med 52(8): 1171-1172.

Buckley AF, Kakar S (2007) Comparison of the dako EGFR pharmDx kit and zymed EGFR antibody for assessment of EGFR status in colorectal adenocarcinoma. Appl Immunohistochem 15(3): 305-309.

Camp RL, Charette LA, Rimm DL (2000) Validation of tissue microarray technology in breast carcinoma. Lab Invest 80(12): 1943-1949.

Carrasquillo JA, Pandit-Taskar N, O’Donoghue JA, Humm JL, Zanzonico P, Smith-Jones PM, Divgi CR, Pryma DA, Ruan S, Kemeny NE, Fong Y, Wong D, Jaggi JS, Scheinberg DA, Gonen M, Panageas KS, Ritter G, Jungbluth AA, Old LJ, Larson SM (2011) 124I-huA33 antibody PET of colorectal cancer. J Nucl Med 52(8): 1173-1180.

Chen L, Wang Y, Cheng D, Dou S, Liu X, Liu G, Hnatowich DJ, Rusckowski M (2011) Comparing two TAG-72 binding peptides previously identified by phage display as potential imaging agents. Nucl Med Commun 32(10): 920-924.

Chen L, Wang Y, Liu X, Dou S, Liu G, Hnatowich DJ, Rusckowski M (2008) A new TAG-72 cancer marker peptide identified by phage display. Cancer Lett 272(1): 122-132.

Chen W-T, Khazaie K, Zhang G, Weissleder R, Tung C-H (2005) Detection of dysplastic intestinal adenomas using a fluorescent folate imaging probe. Mol Imaging 4(1): 67-74.

Conaghan PJ, Ashraf SQ, Tytherleigh MG, Wilding JL, Tchilian E, Bicknell D, Mortensen NJ, Bodmer WF (2008) Targeted killing of colorectal cancer cell lines by a humanised IgGl monoclonal antibody that binds to membrane-bound carcinoembryonic antigen. Br J Cancer 98(7): $1217-1225$.

Dawson PM, Blair SD, Begent RHJ, Kelly AMB, Boxer GM, Theodorou NA (1991) The value of radioimmunoguided surgery in 1st and 2nd look laparotomy for colorectal-cancer. Dis Colon Rectum 34(3): 217-222.

de Jong GM, Bleichrodt RP, Eek A, WJG Oyen, Boerman OC, Hendriks T (2011) Experimental study of radioimmunotherapy versus chemotherapy for colorectal cancer. Br J Surg 98(3): 436-441.

Goetz M, Ziebart A, Foersch S, Vieth M, Waldner MJ, Delaney P, Galle PR, Neurath MF, Kiesslich R (2010) In vivo molecular imaging of colorectal cancer with confocal endomicroscopy by targeting epidermal growth factor receptor. Gastroenterology 138(2): 435-446.

Guillou PJ, Quirke P, Thorpe H, Walker J, Jayne DG, Smith AMH, Heath RM, Brown JM (2005) Short-term endpoints of conventional versus laparoscopic-assisted surgery in patients with colorectal cancer (MRC CLASICC trial): multicentre, randomised controlled trial. The Lancet 365(9472): 1718-1726.

Heine M, Nollau P, Masslo C, Nielsen P, Freund B, Bruns OT, Reimer R, Hohenberg H, Peldschus K, Ittrich H, Schumacher U (2011) Investigations on the usefulness of CEACAMs as potential imaging targets for molecular imaging purposes. PLoS ONE 6(12): e28030.

Jantscheff P, Terracciano L, Lowy A, Glatz-Krieger K, Grunert F, Micheel B, Brümmer J, Laffer U, Metzger U, Herrmann R, Rochlitz C (2003) Expression of CEACAM6 in resectable colorectal cancer: a factor of independent prognostic significance. J Clin Oncol 21(19): 3638-3646.

Jeong M-H, Kim K, Kim E-M, Cheong S-J, Lee C-M, Jeong H-J, Kim DW, Lim ST, Sohn M-H, Chung J (2012) In vivo and in vitro evaluation of Cy5.5 conjugated epidermal growth factor receptor binding peptide. Nucl Med Biol 39(6): 805-812. 
Johnson VG, Schlom J, Paterson AJ, Bennett J, Magnani JL, Colcher D (1986) Analysis of a human tumor-associated glycoprotein (tag-72) identified by monoclonal-antibody b72.3. Cancer Res 46(2): 850-857.

Kaushal S, McElroy MK, Luiken GA, Talamini MA, Moossa AR, Hoffman RM, Bouvet M (2008) Fluorophore-conjugated anti-CEA antibody for the intraoperative imaging of pancreatic and colorectal cancer. J Gastrointest Surg 12(11): 1938-1950.

Kopansky E, Shamay Y, David A (2011) Peptide-directed HPMA copolymerdoxorubicin conjugates as targeted therapeutics for colorectal cancer. $J$ Drug Target 19(10): 933-943.

Koppe MJ, Bleichrodt RP, Oyen WJG, Boerman OC (2005) Radioimmunotherapy and colorectal cancer. Br J Surg 92(3): 264-276.

Koretz K, Schlag P, Moller P (1990) Expression of epidermal growth-factor receptor in normal colorectal mucosa, adenoma, and carcinoma. Virchows Arc A Pathol Anat Histopathol 416(4): 343-349.

Lee JC, Wang ST, Chow NH, Yang HB (2002) Investigation of the prognostic value of coexpressed erbB family members for the survival of colorectal cancer patients after curative surgery. Eur J Cancer 38(8): 1065-1071.

Li P, Wang Y, Zeng F, Chen L, Peng Z, Kong LX (2011) Synthesis and characterization of folate conjugated chitosan and cellular uptake of its nanoparticles in HT-29 cells. Carbohydr Res 346(6): 801-806.

Mahmood U (2010) Optical molecular imaging approaches in colorectal cancer. Gastroenterology 138(2): 419-422.

Maraqa L, Cummings M, Peter MB, Shaaban AM, Horgan K, Hanby AM, Speirs V (2008) Carcinoembryonic antigen cell adhesion molecule 6 predicts breast cancer recurrence following adjuvant tamoxifen. Clin Cancer Res 14(2): 405-411.

Meller B, Rave-Fraenck M, Breunig C, Schirmer M, Baehre M, Nadrowitz R, Liersch T, Meller J (2011) Novel carcinoembryonic-antigen-(CEA)specific pretargeting system to assess tumor cell viability after irradiation of colorectal cancer cells. Strahlenther Onkol 187(2): 120-126.

Meredith RF, Khazaeli MB, Plott WE, Grizzle WE, Liu T, Schlom J, Russell CD, Wheeler RH, LoBuglio AF (1996) Phase II study of dual 131I-labeled monoclonal antibody therapy with interferon in patients with metastatic colorectal cancer. Clin Cancer Res 2(11): 1811-1818.

Meyer T, Gaya AM, Dancey G, Stratford MRL, Othman S, Sharma SK, Wellsted D, Taylor NJ, Stirling JJ, Poupard L, Folkes LK, Chan P-s, Pedley RB, Chester KA, Owen K, Violet JA, Malaroda A, Green AJ, Buscombe J, Padhani AR, Rustin GJ, Begent RH (2009) A phase I trial of radioimmunotherapy with 131I-A5B7 anti-CEA antibody in combination with combretastatin-A4-phosphate in advanced gastrointestinal carcinomas. Clin Cancer Res 15(13): 4484-4492.

Muguruma N, Ito S, Bando T, Taoka S, Kusaka Y, Hayashi S, Ichikawa S, Matsunaga Y, Tada Y, Okamura S, Ii K, Imaizumi K, Nakamura K, Takesako K, Shibamura S (1999) Labeled carcinoembryonic antigen antibodies excitable by infrared rays: A novel diagnostic method for micro cancers in the digestive tract. Intern Med 38(7): 537-542.

O’Donoghue JA, Smith-Jones PM, Humm JL, Ruan S, Pryma DA, Jungbluth AA, Divgi CR, Carrasquillo JA, Pandit-Taskar N, Fong Y, Strong VE, Kemeny NE, Old LJ, Larson SM (2011) 124I-huA33 antibody uptake is driven by A33 antigen concentration in tissues from colorectal cancer patients imaged by immuno-PET. J Nucl Med 52(12): 1878-1885.

Povoski S, Hatzaras I, Mojzisik C, Arnold M, Hinkle G, Hitchcock C, Young D, Martin E (2012) Antigen-directed cancer surgery for primary colorectal cancer: 15-year survival analysis. Ann Surg Oncol 19(1): 131-138.

Qi S, Miao Z, Liu H, Xu Y, Feng Y, Cheng Z (2012) Evaluation of Four Affibody based Near-infrared Fluorescent Probes for Optical Imaging of Epidermal Growth Factor Receptor Positive Tumors. Bioconjug Chem; e-pub ahead of print 4 June 2012.

Reddy JA, Low PS (1998) Folate-mediated targeting of therapeutic and imaging agents to cancers. Crit Rev Ther Drug Carrier Syst 15(6): 587-627.

Scartozzi M, Bearzi I, Berardi R, Mandolesi A, Fabris G, Cascinu S (2004) Epidermal growth factor receptor (EGFR) status in primary colorectal tumors does not correlate with EGFR expression in related metastatic sites: implications for treatment with EGFR-targeted monoclonal antibodies. $J$ Clin Oncol 22(23): 4772-4778.

Schoffelen R, Sharkey RM, Goldenberg DM, Franssen G, McBride WJ, Rossi EA, Chang C-H, Laverman P, Disselhorst JA, Eek A, van der Graaf WTA,
Oyen WJG, Boerman OC (2010) Pretargeted immuno-positron emission tomography imaging of carcinoembryonic antigen-expressing tumors with a bispecific antibody and a Ga-68- and F-18-labeled hapten peptide in mice with human tumor xenografts. Mol Cancer Ther 9(4): 1019-1027.

Schoffelen R, van der Graaf WT, Sharkey RM, Franssen GM, McBride WJ, Chang C-H, Laverman P, Goldenberg DM, Oyen WJ, Boerman OC (2012) Pretargeted immuno-PET of CEA-expressing intraperitoneal human colonic tumor xenografts: a new sensitive detection method. EJNMMI Res 2: 5-5.

Sharkey RM, Cardillo TM, Rossi EA, Chang CH, Karacay H, McBride WJ, Hansen HJ, Horak ID, Goldenberg DM (2005) Signal amplification in molecular imaging by pretargeting a multivalent, bispecific antibody. Nat Med 11(11): 1250-1255.

Shia J, Klimstra DS, Nitzkorski JR, Low PS, Gonen M, Landmann R, Weiser MR, Franklin WA, Prendergast FG, Murphy L, Tang LH, Temple L, Guillem JG, Wong WD, Paty PB (2008) Immunohistochemical expression of folate receptor [alpha] in colorectal carcinoma: patterns and biological significance. Hum Pathol 39(4): 498-505.

Smith AE, Pinkney M, Piggott NH, Calvert H, Milton ID, Lunec J (2007) Novel monoclonal antibody for detection of folate receptor alpha in paraffin-embedded tissues. Hybridoma 26(5): 281-288.

Spano J-P, Lagorce C, Atlan D, Milano G, Domont J, Benamouzig R, Attar A, Benichou J, Martin A, Morere J-F, Raphael M, Penault-Llorca F, Breau J-L, Fagard R, Khayat D, Wind P (2005) Impact of EGFR expression on colorectal cancer patient prognosis and survival. Ann Oncol 16(1): 102-108.

Sun D, Bloomston M, Hinkle G, Al-Saif OH, Hall NC, Povoski SP, Arnold MW, Martin EW (2007) Radioimmunoguided surgery (RIGS), PET/CT image-guided surgery, and fluorescence image-guided surgery: Past, present, and future. J Surg Oncol 96(4): 297-308.

Tang Y, Yang S, Gariépy J, Scollard DA, Reilly RM (2007) Construction and evaluation of the tumor imaging properties of 123I-labeled recombinant and enzymatically generated fab fragments of the TAG-72 monoclonal antibody CC49. Bioconjug Chem 18(3): 677-684.

Tiernan JP, Ansari I, Hirst NA, Millner PA, Hughes TA, Jayne DG (2012) Intra-operative tumour detection and staging in colorectal cancer surgery. Colorectal Dis 14(9): e510-20.

Torhorst J, Bucher C, Kononen J, Haas P, Zuber M, Kochli OR, Mross F, Dieterich H, Moch H, Mihatsch M, Kallioniemi OP, Sauter G (2001) Tissue microarrays for rapid linking of molecular changes to clinical endpoints. Am J Pathol 159(6): 2249-2256.

Vigor KL, Kyrtatos PG, Minogue S, Al-Jamal KT, Kogelberg H, Tolner B, Kostarelos K, Begent RH, Pankhurst QA, Lythgoe MF, Chester KA (2010) Nanoparticles functionalised with recombinant single chain Fv antibody fragments $(\mathrm{scFv})$ for the magnetic resonance imaging of cancer cells. Biomaterials 31(6): 1307-1315.

Yang S-J, Lin F-H, Tsai K-C, Wei M-F, Tsai H-M, Wong J-M, Shieh M-J (2010) Folic acid-conjugated chitosan nanoparticles enhanced protoporphyrin IX accumulation in colorectal cancer cells. Bioconjug Chem 21(4): 679-689.

Yazaki PJ, Kassa T, Cheung C-w, Crow DM, Sherman MA, Bading JR, Anderson A-LJ, Colcher D, Raubitschek A (2008) Biodistribution and tumor imaging of an anti-CEA single-chain antibody-albumin fusion protein. Nucl Med Biol 35(2): 151-158.

Zhang L, Zhu W, Yang C, Guo H, Yu A, Ji J, Gao Y, Sun M, Zhai G (2012) A novel folate-modified self-microemulsifying drug delivery system of curcumin for colon targeting. Int J Nanomedicine 7: 151-162.

Zou P, Xu S, Povoski SP, Wang A, Johnson MA, Martin EW, Subramaniam V, Xu R, Sun D (2009) Near-infrared fluorescence labeled anti-TAG-72 monoclonal antibodies for tumor imaging in colorectal cancer xenograft mice. Mol Pharm 6(2): 428-440.

(c) (1) (2) This work is licensed under the Creative Commons Attribution-NonCommercial-Share Alike 3.0 Unported License. To view a copy of this license, visit http://creativecommons. org/licenses/by-nc-sa/3.0/

Supplementary Information accompanies this paper on British Journal of Cancer website (http://www.nature.com/bjc) 